\title{
ADIÇÃO DE INULINA EM BOLO DE CHOCOLATE: COMPOSIÇÃO FÍSICO- QUÍMICA E SENSORIAL
}

\author{
Thamara Lotici \\ Nutricionista, formada pela Universidade Estadual do Centro-Oeste (UNICENTRO), \\ Guarapuava, PR. thamaralotici@ hotmail.com \\ Elisvânia Freitas dos Santos \\ Doutora, Professora Adjunta do Curso de Nutrição, Docente do Curso de Nutrição da \\ Universidade Federal do Mato Grosso do Sul (UFMS), Campo Grande, MS. \\ elisvania@gmail.com \\ Daiana Novello \\ Doutora, Professora Adjunta do Curso de Nutrição, Docente do Mestrado Interdisciplinar \\ em Desenvolvimento Comunitário da Universidade Estadual do Centro-Oeste \\ (UNICENTRO), Guarapuava, PR. Líder do Grupo de Pesquisa em Ciências da \\ Alimentação e Nutrição da UNICENTRO. nutridai@ hotmail.com \\ Maria Raquel Manhani \\ Doutora, Professora Adjunta do Curso de Nutrição, Docente do Departamento de Farmácia \\ e Nutrição da Universidade São Judas Tadeu (USJT), São Paulo, SP. \\ rmanhani@yahoo.com.br \\ Fabiane La Flor Ziegler Sanches \\ Doutora, Professora Adjunta do Curso de Nutrição, Docente do Curso de Nutrição da \\ Universidade Federal do Mato Grosso do Sul (UFMS), Campo Grande, MS. \\ fabianelaflor@gmail.com.
}

\section{RESUMO}

O desenvolvimento de novos alimentos benéficos à saúde apresenta grande destaque industrial. Dentre eles, estão os produtos contendo ingredientes funcionais como a inulina. O presente estudo objetivou verificar a aceitabilidade sensorial de bolo de chocolate adicionado de inulina e determinar a composição físico-química da formulação tradicional e daquela contendo maior teor de inulina e com aceitação sensorial semelhante a padrão. Foram desenvolvidas as seguintes formulações de bolo de chocolate: F1 (padrão) e as demais adicionadas de 4\% (F2), $8 \%$ (F3), 12\% (F4) e 16\% (F5) de inulina. Participaram da avaliação sensorial 110 provadores não treinados, de ambos os gêneros, com idade entre 18 e 50 anos. Nas análises físico-químicas foram determinados o teor de umidade, cinzas, proteínas, lipídios, carboidratos, fibra alimentar e valor calórico. Os resultados da análise sensorial demonstraram que F1 apresentou maior aceitação que F5 nos atributos aparência, sabor, textura, aceitação global e intenção de compra. Não houve diferença estatística entre as demais amostras (p>0,05). A formulação F1 apresentou maiores teores de carboidratos e calorias quando comparada a F4, sendo que conteúdos mais elevados de umidade e fibra alimentar foram observados em F4. Assim, a elaboração dos produtos permitiu comprovar que um nível de adição de até $12 \%$ de inulina em bolo de chocolate foi bem aceito pelos provadores, obtendo-se aceitação sensorial semelhante ao produto padrão e com boas expectativas de comercialização.

PALAVRAS-CHAVE: Fibras, cereais, frutooligossacarídeos. 


\title{
ADDITION OF INULIN CHOCOLATE CAKE: PHYSICO-CHEMICAL AND SENSORY COMPOSITION
}

\begin{abstract}
The development of new foods beneficial to health has great industrial prominence. Among them are the products containing functional ingredients such as inulin. The present study aimed to verify the sensory acceptability of chocolate cake added inulin and determine the physico-chemical composition of the traditional formulation and that containing a higher content of inulin and with sensory acceptance similar to standard. We developed the following formulations of chocolate cake: F1 (Standard), and the other added 4\% (F2), 8\% (F3), 12\% (F4) and 16\% (F5) inulin. Participated in the sensory evaluation 110 untrained, of both genders, aged between 18 and 50 years. In the physicochemical analyzes were determined moisture content, ash, protein, lipids, carbohydrates, dietary fiber and calorie content. The results of the sensory analysis showed that F1 showed greater acceptance that F5 appearance, taste and texture attributes, and overall acceptance and purchase intent. There was no statistical difference between the other samples ( $>0.05)$. The formulation F1 showed higher levels of carbohydrates and calories compared to F4, with higher moisture content and dietary fiber were observed in F4. Thus, the development of products able to prove that adding a level of up to $12 \%$ inulin in chocolate cake was well received by the judges, obtaining sensory acceptance similar to the standard product and good marketing expectations.
\end{abstract}

KEYWORDS: Fibers, cereals, fructooligosaccharides.

\section{ADIÇÃO DE INULINA EM BOLO DE CHOCOLATE: COMPOSIÇÃO FÍSICO-QUÍMICA E SENSORIAL}

\section{INTRODUÇÃO}

Atualmente o consumidor está cada vez mais exigente e preocupado com a saúde, buscando consumir alimentos com maior qualidade nutricional (ALBUQUERQUE et al., 2009). Dentre eles estão àqueles considerados prebióticos como, por exemplo, a inulina que é uma fibra solúvel, comumente extraída da raiz da chicória e que oferece vários benefícios nutricionais e biológicos. Para o sistema digestivo, esse alimento melhora o equilíbrio da microbiota intestinal, aumentando significativamente a quantidade de bifidobactérias benéficas, elevando dessa forma a absorção dos nutrientes ingeridos (BORTOLOZO; QUADROS, 2007).

Os frutanos inulina e oligofrutose são os carboidratos não-disponíveis mais investigados em estudos envolvendo seres humanos e são os únicos em que foi cientificamente comprovado serem resistentes à acidez gástrica, à hidrólise das enzimas e à absorção gastrointestinal (CAPRILES; ARÊAS, 2012).

A aplicação da inulina na indústria de alimentos deve-se, principalmente, às suas propriedades que as tornam capaz de substituir o açúcar e/ou gordura, com a vantagem de não resultar em aumento calórico, sendo bastante utilizada em países da Europa, Estados Unidos e Canadá (TOLONI et al., 2011). A inulina é vastamente aplicada como 
ingrediente em uma série de alimentos, tais como, bolos, produtos lácteos, dentre outros (WONG et al., 2010; VOLPINI-RAPINA et al., 2012; ZIOBRO et al., 2013).

Alimentos como os bolos são muito estudados atualmente devido ao seu alto consumo e seu apelo à saudabilidade. O mercado desses produtos movimentou no Brasil $\mathrm{R} \$ 514$ milhões, com consumo per capita de 1,4 kg no ano de 2009 (ABIMA, 2013). Entretanto, as regras sobre o seu uso podem variar entre os países. No Brasil, a legislação aprova a alegação de que a inulina ajuda a equilibrar a flora intestinal, uma vez que seu consumo está associado a uma dieta equilibrada e estilo de vida saudável, desde que a ingestão seja acompanhada líquidos. Além disso, porções de alimentos sólidos devem conter pelo menos $3 \mathrm{~g}$ de inulina para essa reivindicação (BRASIL, 2011). Apesar de seus benefícios, a incorporação de inulina em bolos pode provocar alterações nos atributos sensoriais e tecnológicos dos produtos, o que também pode influenciar sua aceitabilidade pelos consumidores (VOLPINI-RAPINA et al., 2012).

Para que novos produtos sejam oferecidos aos consumidores torna-se necessária sua avaliação constate através da utilização de ferramentas como a análise sensorial. Por meio desta técnica pode-se definir a qualidade de um produto, avaliar a percepção e a reação dos consumidores diante das características de um alimento, analisar a qualidade inferior ou superior aos produtos concorrentes ou originais, determinar as características sensoriais como sabor, textura, cor, aroma e intensidade, prevendo a aceitação do alimento (GULARTE, 2002). Sobre estas informações incidem importantes decisões como seleção da matéria-prima, padronização de métodos e otimização de formulações, para o desenvolvimento de novos produtos, tornando-se assim um instrumento básico para aplicação na indústria alimentícia (MEHINAGIC et al., 2003).

Diante do exposto, o objetivo deste estudo foi desenvolver formulações de bolo de chocolate adicionadas de inulina e avaliar a aceitabilidade sensorial, bem como comparar a composição físico-química do produto com maior teor de inulina e aceitação semelhante ao padrão.

\section{MATERIAL E MÉTODOS}

\section{Obtenção da matéria-prima}

Os produtos foram adquiridos em supermercados do município de Guarapuava, PR e a inulina foi doada por empresas nacionais parceiras.

\section{Formulações}

Foram elaboradas cinco formulações de bolo de chocolate, sendo: F1 padrão (0\%) e as demais adicionadas de 4\% (F2), 8\% (F3), 12\% (F4) e 16\% (F5) de inulina. Estes níveis de adição foram definidos através de testes sensoriais preliminares realizados com o produto. Na Tabela 1 podem ser verificadas as formulações dos bolos adicionados de inulina.

Tabela 1. Ingredientes das formulações de bolos de chocolate adicionadas de inulina

\begin{tabular}{|l|c|c|c|c|c|}
\hline Ingredientes & F1 & F2 & F3 & F4 & F5 \\
\hline Farinha de trigo (\%) & 21,64 & 21,64 & 21,64 & 21,64 & 21,64 \\
\hline Leite integral (\%) & 19,84 & 19,84 & 19,84 & 19,84 & 19,84 \\
\hline Açúcar refinado (\%) & 16,00 & 12,00 & 8,00 & 4,00 & 0,00 \\
\hline Óleo de soja (\%) & 16,37 & 16,37 & 16,37 & 16,37 & 16,37 \\
\hline
\end{tabular}




\begin{tabular}{|l|c|c|c|c|c|}
\hline \hline Ovo inteiro (\%) & 13,36 & 13,36 & 13,36 & 13,36 & 13,36 \\
\hline Achocolatado em pó (\%) & 11,79 & 11,79 & 11,79 & 11,79 & 11,79 \\
\hline Fermento em pó químico (\%) & 1,00 & 1,00 & 1,00 & 1,00 & 1,00 \\
\hline Inulina em pó (\%) & 0,00 & 4,00 & 8,00 & 12,00 & 16,00 \\
\hline
\end{tabular}

As formulações foram preparadas, individualmente, no Laboratório de Técnica Dietética do Departamento de Nutrição da UNICENTRO. A pesagem de todos os ingredientes foi realizada em uma balança digital (Filizola ${ }^{\circledR}$, Brasil) com precisão de $0,1 \mathrm{~g}$ e capacidade máxima de $15 \mathrm{~kg}$.

Inicialmente, os ingredientes líquidos foram misturados em batedeira doméstica (Britania ${ }^{\circledR}$, Brasil) juntamente com o açúcar por aproximadamente 5 minutos, até se obter uma consistência homogênea. A esta mistura foi adicionada os ingredientes secos e, por último, o fermento em pó químico, sendo homogeneizada manualmente por mais 3 minutos. Após este processo, as formulações foram dispostas em formas de alumínio untadas com óleo e assadas em forno convencional (Dako ${ }^{\circledR}$, Brasil) pré-aquecido a $180{ }^{\circ} \mathrm{C}$ por 40 minutos.

\section{Análise Sensorial}

Participaram da pesquisa 110 provadores não treinados constituídos por alunos, funcionários e professores da UNICENTRO, de ambos os gêneros, com idade entre 18 e 50 anos.

Os testes sensoriais dos produtos avaliaram os atributos: aparência, aroma, sabor, textura e cor. Os provadores julgaram a aceitação das amostras através de uma escala hedônica estruturada de 9 pontos (1: desgostei muitíssimo a 9: gostei muitíssimo), segundo Dutcosky (2011). Foram aplicadas também, questões de aceitação global avaliadas através de uma escala hedônica estruturada de 9 pontos e intenção de compra analisados através de uma escala hedônica estruturada de 5 pontos (1: não compraria a 5: compraria com certeza), como sugerido por Minim (2010).

Para complementação da pesquisa, realizou-se o teste de comparação múltipla, onde cada provador comparou as amostras de bolo de chocolate adicionadas de inulina, individualmente, com um bolo de mesmo sabor amplamente comercializado no mercado (referência - sem adição de inulina). Cada julgador identificou se os produtos contendo inulina apresentavam sabor melhor, igual ou pior ao bolo referência, através de uma escala hedônica estruturada de 9 pontos, variando da nota 1 (Extremamente pior que a referência) a nota 9 (Extremamente melhor que a referência), como sugerido por Dutckoski (2011).

Cada julgador recebeu uma porção de cada amostra (aproximadamente $25 \mathrm{~g}$ ), em pratos plásticos brancos codificados com números de três dígitos, de forma casualizada e balanceada, acompanhados de água para realização do branco entre as amostras. As formulações foram oferecidas aos julgadores de forma monádica sequencial. 


\section{Índice de aceitabilidade (IA)}

O cálculo do índice de aceitabilidade das cinco formulações foi realizado conforme Monteiro (1984), segundo a fórmula: IA $(\%)=A \times 100 / B(A=$ nota média obtida para $o$ produto; $B=$ nota máxima dada ao produto).

\section{Composição físico-química}

As análises físico-químicas foram realizadas no Laboratório de Análise de Alimentos do Departamento e Engenharia de Alimentos da UNICENTRO e no Laboratório de Bromatologia e Composição de Alimentos da Universidade São Judas Tadeu, São Paulo, SP.

As seguintes determinações foram realizadas, em triplicata, na formulação padrão e naquela com maior teor de inulina e com aceitação sensorial semelhante a padrão: Umidade: determinada em estufa a $105{ }^{\circ} \mathrm{C}$ até o peso constante (AOAC, 2011); Cinzas: Analisadas em mufla $\left(550{ }^{\circ} \mathrm{C}\right)$, conforme AOAC (2011); Lipídios totais: Utilizou-se o método de extração a frio (BLIGH; DYER, 1959); Proteínas: Avaliadas através do teor de nitrogênio total da amostra, pelo método Kjeldahl, determinado ao nível semimicro (AOAC, 2011). Utilizou-se o fator de conversão de nitrogênio para proteína de 6,25; Fibra Alimentar: Foi realizado o cálculo teórico das formulações através do programa Avanutri ${ }^{\circledR}$ 3.0 (2013); Carboidratos: A determinação de carboidratos (incluindo fibra) dos produtos foi realizada através de cálculo teórico (por diferença) nos resultados das triplicatas, conforme a fórmula: \% Carboidratos $=100-(\%$ umidade $+\%$ proteína $+\%$ lipídios $+\%$ cinzas); Valor calórico: O total de calorias (kcal) foi calculado utilizando os seguintes valores: lipídios $(8,37 \mathrm{kcal} / \mathrm{g})$, proteína $(3,87 \mathrm{kcal} / \mathrm{g})$, carboidratos $(4,11 \mathrm{kcal} / \mathrm{g})$ (MERRILL; WATT, 1973) e inulina: 1,5 kcal/g (carboidratos) (BENEO $\left.{ }^{\circledR} \mathrm{HP}, 2013\right)$.

\section{Determinação do Valor Diário de Referência (VD)}

O VD foi calculado, em relação a $50 \mathrm{~g}$ da amostra, com base nos valores preconizados para adultos de 18 a 50 anos (DRI, 2005). Os nutrientes foram avaliados pelo cálculo médio dos provadores, resultando em: 1935,67 kcal/dia, 250,88 $\mathrm{g}$ de carboidratos, 69,18 $\mathrm{g}$ de proteínas, 70,26 g de lipídios e 12,75 g de fibra alimentar.

\section{Questões éticas}

Este trabalho foi aprovado pelo Comitê de Ética em Pesquisa da UNICENTRO, parecer número $n^{\circ}$ 49549/2012. Entretanto, como critérios de exclusão foram considerados os seguintes fatores: possuir alergia a algum ingrediente utilizado na elaboração dos bolos ou não entregar o Termo de Consentimento Livre e Esclarecido (TCLE) assinado.

\section{Análise Estatística}

Os dados foram analisados com auxílio do software Statgraphics Plus ${ }^{\circledR}$, versão 5.1, através da análise de variância (ANOVA), sendo que a comparação de médias foi realizada pelo teste de Tukey, t de student e Dunnett, com nível de 5\% de significância. 


\section{RESULTADOS E DISCUSSÃO}

\section{Análise sensorial}

Por meio da Tabela 2 pode-se verificar o resultado da avaliação sensorial dos bolos de chocolate padrão e acrescidos de inulina.

Tabela 2. Médias do teste sensorial afetivo e de intenção de compra realizados para as formulações de bolo de chocolate adicionadas de inulina

\begin{tabular}{|l|c|c|c|c|c|}
\hline Atributos & $\begin{array}{c}\text { F1 } \\
\text { Média } \pm D P\end{array}$ & $\begin{array}{c}\text { F2 } \\
\text { Média } \pm D P\end{array}$ & $\begin{array}{c}\text { F3 } \\
\text { Média } \pm D P\end{array}$ & $\begin{array}{c}\text { F4 } \\
\text { Média } \pm D P\end{array}$ & $\begin{array}{c}\text { F5 } \\
\text { Média } \pm D P\end{array}$ \\
\hline Aparência & $7,28 \pm 1,02^{\mathrm{a}}$ & $7,22 \pm 1,25^{\mathrm{a}}$ & $7,26 \pm 1,41^{\mathrm{a}}$ & $7,11 \pm 1,31^{\mathrm{a}}$ & $6,13 \pm 1,84^{\mathrm{b}}$ \\
\hline Aroma & $7,32 \pm 1,23^{\mathrm{a}}$ & $7,3 \pm 1,24^{\mathrm{a}}$ & $7,18 \pm 1,53^{\mathrm{a}}$ & $7,12 \pm 1,42^{\mathrm{a}}$ & $6,95 \pm 1,44^{\mathrm{a}}$ \\
\hline Sabor & $7,38 \pm 1,15^{\mathrm{a}}$ & $7,42 \pm 1,06^{\mathrm{a}}$ & $7,40 \pm 1,25^{\mathrm{a}}$ & $7,04 \pm 1,50^{\mathrm{ab}}$ & $6,43 \pm 2,05^{\mathrm{b}}$ \\
\hline Textura & $7,55 \pm 1,21^{\mathrm{a}}$ & $7,51 \pm 1,15^{\mathrm{a}}$ & $7,57 \pm 1,29^{\mathrm{a}}$ & $7,34 \pm 1,19^{\mathrm{a}}$ & $6,15 \pm 2,15^{\mathrm{b}}$ \\
\hline Cor & $7,0 \pm 1,18^{\mathrm{a}}$ & $7,16 \pm 1,27^{\mathrm{a}}$ & $7,10 \pm 1,47^{\mathrm{a}}$ & $6,89 \pm 1,40^{\mathrm{a}}$ & $6,66 \pm 1,35^{\mathrm{a}}$ \\
\hline Aceitação Global & $7,25 \pm 1,21^{\mathrm{a}}$ & $7,36 \pm 1,17^{\mathrm{a}}$ & $7,33 \pm 1,32^{\mathrm{a}}$ & $7,04 \pm 1,30^{\mathrm{ab}}$ & $6,28 \pm 1,36^{\mathrm{b}}$ \\
\hline Intenção de Compra & $3,97 \pm 0,78^{\mathrm{a}}$ & $4,14 \pm 0,76^{\mathrm{a}}$ & $4,06 \pm 0,90^{\mathrm{a}}$ & $3,93 \pm 0,80^{\mathrm{a}}$ & $3,38 \pm 1,38^{\mathrm{b}}$ \\
\hline
\end{tabular}

Letras diferentes na linha indicam diferença significativa pelo teste de Tukey $(\mathrm{p}<0,05) ; D P$ : Desvio padrão da média; F1: padrão; F2: 4\% de inulina; F3: 8\% de inulina; F4: 12\% de inulina; F5: $16 \%$ de inulina.

Não houve diferença significativa entre as formulações para os atributos aroma e cor. Resultados discordantes foram verificados por Volpini-Rapina et al. (2012), que avaliaram a aceitação de bolo de laranja adicionado de inulina (29\%), sendo que maiores notas para o aroma foram relatadas para os produtos contendo esse ingrediente. Essa diferença de resultados pode ter ocorrido devido à presença da laranja na formulação dos autores, a qual apresenta um aroma cítrico diferenciado.

Apesar dos provadores não perceberem alterações de coloração entre os produtos, durante a elaboração dos bolos verificou-se visualmente que aqueles contendo maiores teores de inulina apresentaram uma coloração mais escura que as demais. Uma explicação para esse fato seria porque a umidade absorvida pela inulina provoca uma aglomeração deste ingrediente, o qual perde as suas características de pó e passa a ser uma massa sólida e dura, formada pela união de unidades menores, provocando uma mudança na coloração, passando de esbranquiçada para caramelada (TONELI et al., 2008). Resultados semelhantes foram verificados por Hager et al. (2011) e Poinot et al. (2010) onde pães sem glúten adicionados de inulina (4, 8 e 12\%) também apresentaram cores mais escuras.

Quanto aos atributos aparência, textura e a intenção de compra, a formulação F5 apresentou as menores notas pelos provadores $(\mathrm{p}<0,05)$ dentre todas as amostras, porém não houve diferença significativa entre as demais formulações. Destaca-se que as cascas dos bolos enriquecidos com inulina ficaram mais firmes do que a controle, corroborando com resultados de Mandala (2009) que avaliou o efeito da suplementação de inulina (5\%) e frutooligossacarídeos - FOS (8\%) em pães. De forma semelhante, durante a elaboração de F5 a massa apresentou uma textura mais seca que as demais, corroborando com estudos de Zanh et al. (2010), que avaliaram o perfil sensorial de bolo de laranja adicionado de inulina $(29 \%)$ e oligofrutose $(31 \%)$, onde os produtos contendo esses ingredientes tiveram menores notas para textura, sendo relatados como mais secos e rígidos.

Avaliando-se a característica sabor e a aceitação global dos produtos, maiores notas foram observadas nas amostras F1, F2 e F3 comparadas a F5, sendo que não houve diferença 
estatística (p>0,05) entre F4 e as demais formulações. Segundo Ronkart et al. (2009) a adição de inulina aumenta a dureza, promovendo maior friabilidade em produtos como os bolos, o que pode estar relacionada à menor incorporação de bolhas de ar as massas durante o cozimento, contribuindo para uma menor aceitação e maior fragilidade do produto.

A Figura 1 apresenta a distribuição dos provadores pelos valores hedônicos para cada atributo sensorial.
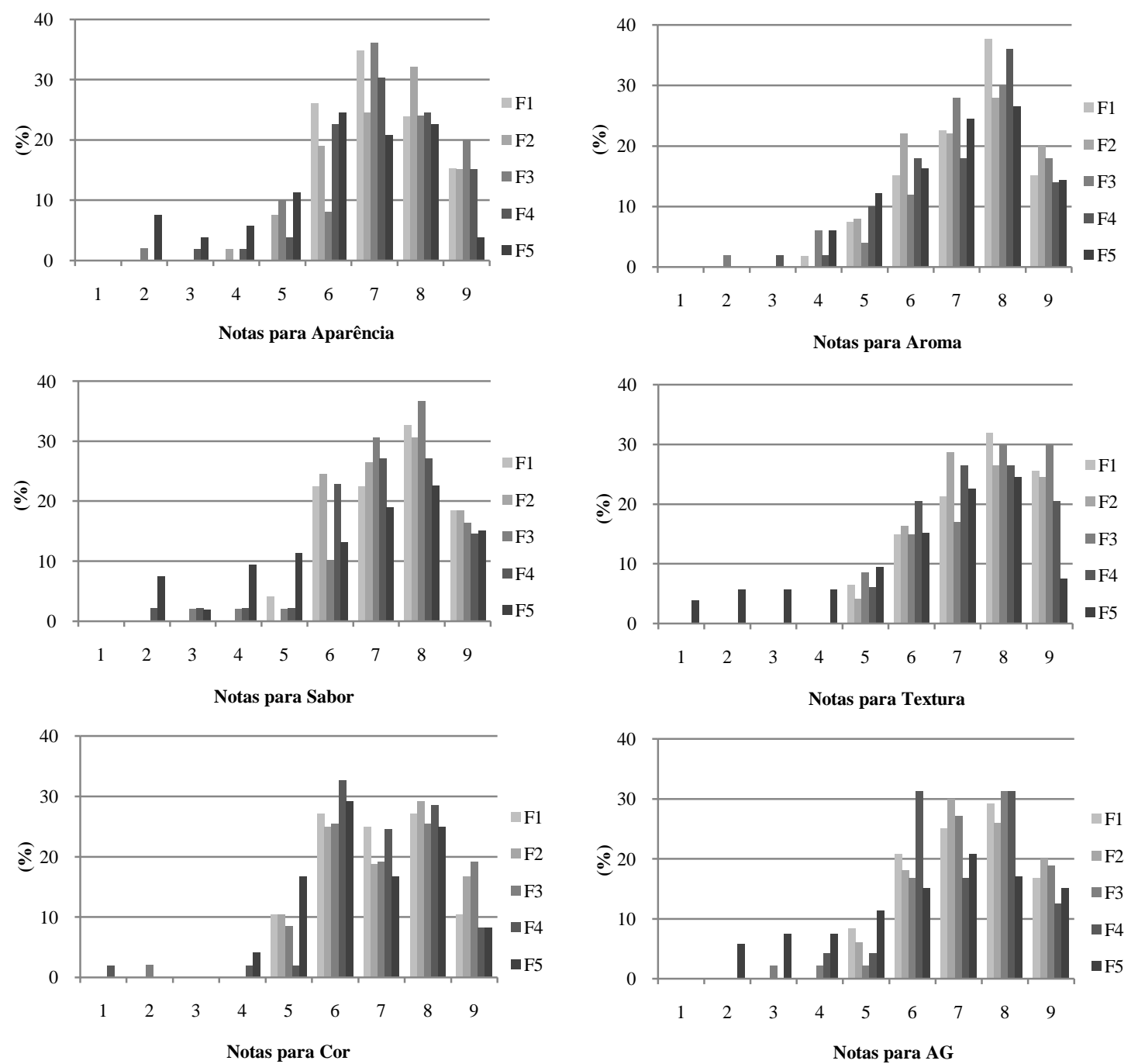

Figura 1. Distribuição dos provadores pelos valores hedônicos obtidos na avaliação dos atributos aparência, aroma, sabor, textura e cor das formulações de bolo de chocolate padrão (F1) e adicionadas de 4\% (F2), $8 \%$ (F3), 12\% (F4) e 16\% (F5) de inulina.

Por meio da Figura 1 observa-se que a maioria das porcentagens das notas conferidas pelos provadores encontram-se acima de 6 ("gostei ligeiramente"), o que demonstra que as formulações foram, em geral, bem aceitas pelos provadores. Entretanto, conforme se adicionou inulina nos produtos as notas reduziram, principalmente em F4 e F5. 
Especialmente no atributo sabor, a adição de $8 \%$ de inulina (F3) foi a amostra que obteve a maior porcentagem de julgamentos na nota 8 ("gostei muito"). Segundo explicam Sendra et al. (2008) e Volpini-Rapina et al. (2012) a adição de prebióticos em alimentos pode elevar o sabor, aumentando dessa forma sua aceitação e consumo. Segundo Wang (2009) a incorporação de prebióticos em produtos de panificação permite, além do aumento no teor e fibras, uma redução no teor de açúcar e maior retenção de água, características que melhoram o perfil nutricional dos alimentos.

Destaca-se que uma possível oferta dos produtos adicionados de inulina poderá promover benefícios nutricionais aos indivíduos, uma vez que a fibra solúvel presente nesse ingrediente reduz o $\mathrm{pH}$ intestinal, o que promove uma maior absorção de nutrientes (WANG, 2009).

Na Figura 2 verifica-se o índice de aceitabilidade das formulações de bolo de chocolate padrão e daquelas adicionadas de inulina em relação aos atributos aparência, aroma, sabor, textura, cor e aceitação global.

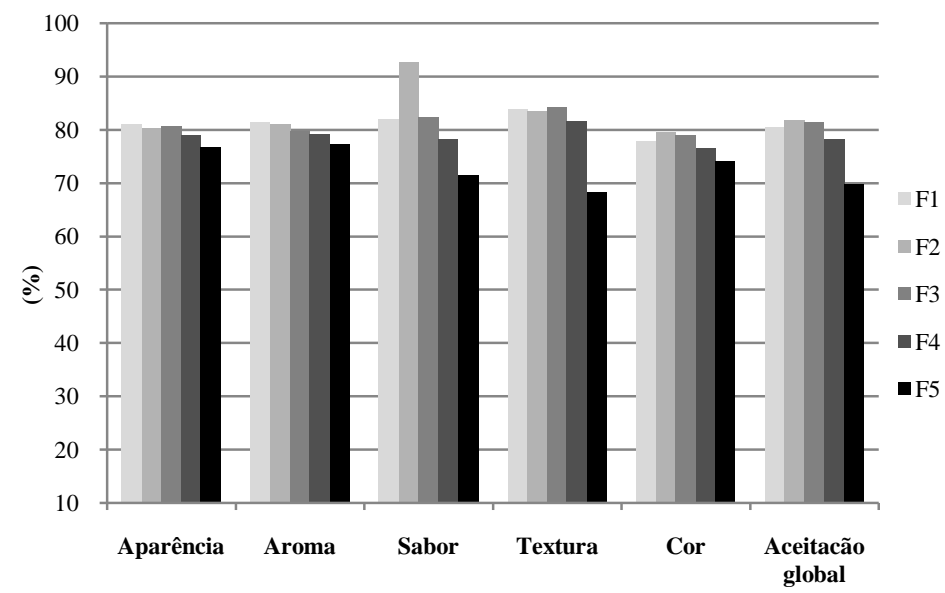

Figura 2. Índice de aceitabilidade das formulações de bolo de chocolate padrão (F1) e adicionadas de $4 \%$ (F2), $8 \%$ (F3), 12\% (F4) e 16\% (F5) de inulina, em relação aos atributos avaliados.

Com exceção da amostra F5 (textura), todas as formulações de bolo apresentaram IA $\geq$ a $70 \%$, que avalia os produtos com boa aceitação sensorial (TEIXEIRA et al., 1987). Esses altos índices de aceitabilidade podem ser explicados, pois segundo Volpini-Rapina et al. (2012) apenas a adição de inulina em bolos não afeta significativamente a aceitação dos atributos, devido à sua baixa capacidade em modificar as propriedades sensoriais.

Na Figura 3 observam-se os resultados do teste de comparação múltipla entre as amostras avaliadas, comparadas com um bolo vendido comercialmente. 


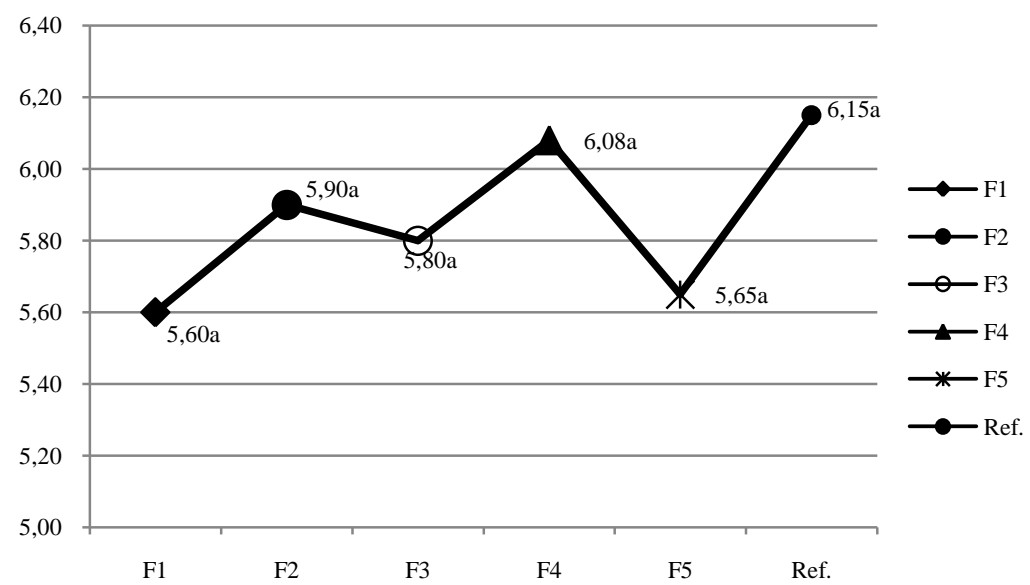

Obs.: Letras diferentes indicam diferença significativa pelo teste de médias de Dunnett $(\mathrm{p}<0,05)$.

Figura 3. Notas do teste de comparação múltipla relacionado ao atributo de sabor, tendo como referência a amostra padrão (F1) e adicionadas de 4\% (F2), $8 \%(F 3)$, $12 \%$ (F4) e $16 \%$ (F5) de inulina e a amostra referência.

Não houve diferença significativa $(\mathrm{p}<0,05)$ entre as formulações e o produto comercializado (referência), sendo considerados com "sabor igual" ao produto referência, corroborando com resultados obtidos por Volpini-Rapina et al. (2012).

Segundo Alamanou et al. (1996), atributos como o aroma e sabor são, provavelmente, as características mais importantes que influenciam as propriedades sensoriais de produtos alimentícios adicionados de ingredientes diferenciados. Em razão disso, a amostra F4 (12\%) foi selecionada para fins de comparação, juntamente com a padrão (F1), por ser aquela com o maior teor de inulina e com aceitação semelhante a padrão.

\section{Composição físico-química}

Na Tabela 3 observa-se a composição físico-química e valores diários recomendados (VD) dos bolos de chocolate padrão e acrescidos de $12 \%$ de inulina, comparados com um produto referência.

Tabela 3. Composição físico-química e valores diários recomendados - VD* (porção média de 50 gramas) do bolo de chocolate padrão (F1) e adicionado de 12\% de inulina (F4), comparadas com um produto referência**

\begin{tabular}{|c|c|c|c|c|c|}
\hline & F1 & & $\mathbf{F 4}$ & & Referência*** $^{* *}$ \\
\hline Avaliação & Média $\pm D P$ & $\begin{array}{l}\text { VD } \\
(\%)^{*}\end{array}$ & Média $\pm D P$ & $\begin{array}{l}\text { VD } \\
(\%)^{*}\end{array}$ & \\
\hline Umidade $(\%)$ & $19,07 \pm 0,06 \mathrm{~b}$ & ND & $23,80 \pm 0,08 \mathrm{a}$ & ND & 19,30 \\
\hline Cinzas $\left(\mathrm{g} .100 \mathrm{~g}^{-1}\right) * * *$ & $1,03 \pm 0,02 \mathrm{a}$ & ND & $1,03 \pm 0,01 \mathrm{a}$ & ND & 1,30 \\
\hline Proteínas $\left(\right.$ g. $\left.100 \mathrm{~g}^{-1}\right) * * *$ & $7,06 \pm 0,08 \mathrm{a}$ & 5,10 & $7,24 \pm 0,03 a$ & 5,23 & 6,20 \\
\hline Lipídios $\left(\mathrm{g} .100 \mathrm{~g}^{-1}\right)^{* * *}$ & $24,30 \pm 0,10 \mathrm{a}$ & 17,29 & $23,69 \pm 0,12 \mathrm{a}$ & 16,85 & 18,50 \\
\hline Carboidratos $\left(\mathrm{g} .100 \mathrm{~g}^{-1}\right)^{* * *}$ & $48,54 \pm 0,65 \mathrm{a}$ & 9,67 & $44,24 \pm 0,48 b$ & 8,81 & 54,70 \\
\hline Calorias $\left(\mathrm{kcal} .100 \mathrm{~g}^{-1}\right)^{* * *}$ & $430,21 \pm 1,11 \mathrm{a}$ & 11,11 & $376,81 \pm 0,98 b$ & 9,73 & 410,00 \\
\hline Fibra alimentar $\left(\text { g. } 100 \mathrm{~g}^{-1}\right)^{* * * *}$ & 0,93 & 3,40 & 12,59 & 49,33 & 1,40 \\
\hline
\end{tabular}


Letras diferentes na linha indicam diferença significativa pelo teste de t de student $(\mathrm{p}<0,05)$; *VD: nutrientes avaliados pela média da DRI (2005), com base numa dieta de 1935,67 kcal/dia; **Valores comparados com "bolo de chocolate" (TACO, 2011); ***Valores calculados em base úmida; ****Cálculo teórico; DP: desvio padrão da média; ND: Não disponível.

Foram verificados maiores teores $(\mathrm{p}<0,05)$ de umidade no bolo de chocolate contendo inulina, sendo que ambas as amostras se apresentaram acima do preconizado pela RDC $\mathrm{n}^{\circ}$ 263 de 22 de setembro de 2005, da Agência Nacional de Vigilância Sanitária (ANVISA), que define um máximo de $15 \%$ de umidade em produtos de panificação (BRASIL, 2005). Resultados semelhantes foram observados por De Soete (2000), avaliando cookies contendo 40, 60 e $80 \%$ de FOS. Segundo os autores os FOS possuem características umectantes, retendo maior umidade.

Não houve diferença significativa no conteúdo de cinzas, proteínas e lipídios, entre as duas amostras. Esses resultados são justificáveis uma vez que tanto a inulina como o açúcar são isentos desses nutrientes em sua composição química (TACO, 2011; BENEO ${ }^{\circledR} \mathrm{HP}, 2013$ ). Esses dados corroboram com Chanu e Sangeeta (2011), avaliando cookies adicionados de FOS $(40,60$ e $80 \%)$.

O fato da amostra padrão conter maior quantidade de carboidratos e calorias comparada a F4 ( $\mathrm{p}<0,05)$ é explicado, pois o açúcar apresenta maiores porcentagens de carboidratos e calorias $(99,6 \mathrm{~g} / 100 \mathrm{~g}$ e $387 \mathrm{kcal}$, respectivamente) (TACO, 2011) quando comparado à inulina (97 g/100 g e $194 \mathrm{kcal}$, respectivamente) $\left(\right.$ BENEO $\left.^{\circledR} \mathrm{HP}, 2013\right)$. Efeitos similares foram relatados em estudos de Brasil et al. (2011) que avaliaram pães adicionados inulina $(0,6$ e $10 \%)$. Esta redução calórica, de aproximadamente $12,41 \%$, obtida na formulação F4 pode colaborar, por exemplo, na prevenção e tratamento de doenças cardiovasculares, diabetes mellitus tipo II e algumas disfunções digestivas, pois a fibra dietética, especialmente a sua fração solúvel, é conhecida por reduzir a ocorrência dessas patologias (ANDERSON et al., 2009; GUNNESS e GIDLEY, 2010).

Destaca-se como principal resultado desse trabalho o teor de fibras verificado na formulação do bolo de chocolate com adição de inulina F4 $\left(12,59 \mathrm{~g} \cdot 100 \mathrm{~g}^{-1}\right)$, expressando um aumento significativo de $1253,80 \%$ em relação a $\mathrm{F} 1$. Isso se deve, principalmente, ao alto teor de fibras $(97 \%)$ presente na inulina $\left(\right.$ BENEO $\left.^{\circledR} \mathrm{HP}, 2013\right)$. Estes resultados tornam o produto uma excelente opção para o consumo, pois evidências científicas têm demonstrado que a inulina possui compostos bioativos capazes de atuar no organismo, produzindo efeitos metabólicos e/ou fisiológicos com benéficos à saúde humana (FORTES, 2005; 2006).

De acordo com a Legislação Brasileira (BRASIL, 1998), um produto é considerado como fonte de fibra alimentar quando apresenta no mínimo 3\% e com alto teor no mínimo $6 \%$ em fibras, assim, a formulação F4 pode ser considerada um produto com alto teor em fibras.

\section{CONCLUSÃO}


O desenvolvimento dos produtos permitiu comprovar que um nível de adição de até $12 \%$ de inulina em bolo de chocolate (redução de $75 \%$ do açúcar), foi bem aceito pelos provadores, obtendo-se aceitação sensorial semelhante ao produto padrão.

A análise físico-química das amostras adicionadas de $12 \%$ de inulina proporcionou redução nos conteúdos de carboidratos e calorias e aumento no teor de umidade. Destacase que a adição de inulina possibilitou um elevado aporte de fibras, melhorando o perfil nutricional do produto.

Assim sendo, a inulina pode ser considerada um potencial ingrediente com propriedades funcionais, para adição em bolos e similares, podendo ser oferecidos aos consumidores com altas expectativas de aceitação no mercado.

\section{REFERÊNCIAS BIBLIOGRÁFICAS}

1. ALAMANOU, S.; DOXASTAKIS, G.; BLOUKAS, J.; PANERAS, D. Influence of protein isolate from lupin seeds on processing and quality characteristics of frankfurters. Meat Science, v.42, n.1, p.79-83, 1996.

2. ALBUQUERQUE, T.L.D.; LIMA, M.D.A.; OLIVEIRA, V.S.D.; COELHO, R.M.D.; RODRIGUES, M.D.CP. Processamento e aceitação sensorial de produto do tipo hambúrguer à base de soja (glycinemax) e atum (Thunnus spp). Boletim do CEPPA Centro de Pesquisa de Processamento de Alimentos, v.27, n.2, p.191-198, 2009.

3. ANDERSON, J.W.; BAIRD, P.; DAVIS, JR.R.H.; FERRERI, S.; KNUDTSON, M.; KORAYM, A.; WATERS, V.; WILLIAMS, C.L; Health benefits of dietary fiber. Nutrition Reviews, v.67, n.4, p.188-205, 2009.

4. AOAC International. Official Methods of Analysis of AOAC International. 18 ed. 4 rev. Gaithersburg: AOAC, 2011. 1505p.

5. ASSOCIAÇÃO BRASILEIRA DAS INDÚSTRIAS DE MASSAS ALIMENTÍCIAS ABIMA. Vendas de bolos no Brasil. Disponível em: http://www.abima.com.br/ Acesso em: 05 de maio de 2013.

6. AVANUTRI 3.0. Software Avanutri. Disponível em: http://www.avanutri.com.br/ Acesso em: 14 de abril de 2013.

7. BENEO $^{\circledR}$ HP. Product Sheet Beneo ${ }^{\circledR}$ HP, Orafti, DOC.A4-05*01/02-B. Disponível em: http://www.orafti.com/ Acesso em: 25 de junho de 2013.

8. BLIGH, E.G.; DYER, W.J. A rapid method of total lipid extraction and purification. Canadian Journal of Biochemistry and Physiology, v.37, n.8, p. 911-917, 1959.

9. BORTOLOZO, E.Q.; QUADROS, M.H.R. Aplicação de inulina e sucralose em iogurte. Revista Brasileira de Tecnologia Agroindustrial, v.1, n.1, p.37-47, 2007.

10. BRASIL, J.A.; SILVEIRA, C.R.; SALGADO, S.M.; LIVEIRA, S.V.A.; FARO, P.Z.; GUERRA, B.N. Effect of the addition of inulin on the nutritional, physical and sensory parameters of bread. Brazilian Journal of Pharmaceutical Sciences, v.47, n.1, p.185-191, 2011.

11. BRASIL. Ministério da Saúde. Portaria $n^{o} .27$, de 13 de janeiro de 1998. Regulamento técnico referente à informação nutricional complementar (declarações relacionadas ao conteúdo de nutrientes) Diário Oficial [da] República Federativa do Brasil. 1998 jan. 13; Seção 1.

12. BRASIL. Agência Nacional de Vigilância Sanitária. $R D C n^{\circ} 263$ de 22 de setembro de 2005. "Regulamento técnico para produtos de cereais, amidos, farinhas e farelos". Diário Oficial da União; Poder Executivo, Brasília, DF, 2005. 
13. CAPRILES, V.D.; ARÊAS, J.A.G. Frutanos do tipo inulina e aumento da absorção de cálcio: uma revisão sistemática. Revista de Nutrição, v.25, n.1, p.147-159, 2012.

14. CHANU, H.; SANGEETA, G. Effects of Whole-Multigrain and Fructoligosaccharide Incorporation on the Quality and Sensory Attributes of Cookies. Food Science and Technology, v.17, n.1, p. 45-54, 2011.

15. DE SOETE, J. Prebiotic ingredients in chewing gum - the use of inulin and oligofructose. The Manufacturing Confectioner, v.80, n.2, p.67-69, 2000.

16. DIETARY REFERENCE INTAKES (DRI). Dietary Reference Intakes for energy, carbohydrate, fiber, fat, fatty acids, cholesterol, protein and amino acids. Washington: The National Academies Press, 2005. 1331p.

17. DUTCOSKY, S.D. Análise sensorial de alimentos. 3. ed. Curitiba: Champagnat, 2011. 427p.

18. FORTES, R.C. Alimentos prebióticos: Efeitos bifidogênicos dos frutooligossacarídeos e da inulina no organismo humano. Revista da Sociedade Espanhola de Farmácia Hospitalaria (SEFH), v.2, n.9, p.16-23, 2006.

19. FORTES, R.C. Os frutooligossacarídeos, a inulina e suas implicações na indústria de alimentos. Nutrição Brasil, v.4, n.1, p.52-61, 2005.

20. GULARTE, M. A. Manual de análise sensorial de alimentos. Pelotas: UFPel, 2002. $59 \mathrm{p}$.

21. GUNNESS, P.; GIDLEY, M.J. Mechanisms underlying the cholesterol-lowering properties of soluble dietary fibre polysaccharides. Food \& Function, v.1, n.2, p.149, 2010.

22. HAGER, A.; RYAN, L.A.M.; SCHWAB, C.; GAENZLE, M.G.; O’DOHERTY, J.V.; ARENDT, E.K.; Influence of the soluble fibres inulin and oat beta-glucan on quality of dough and bread. European Food Research and Technology, v.232, n.3, p.405-413, 2011.

23. MANDALA, I.; POLAKI, A.; YANNIOTIS, S. Influence of frozen storage on breadenriched with different ingredients. Journal of Food Engineering, v.92, n.2, p.137-145, 2009.

24. MEHINAGIC, E.; ROYER, G.; BERTRAND, G.; SYMONEAUX, R.; LAURENS, F.; JOURJON, F. Relationship between sensory analysis, penetrometry and visible NR spectroscopy of apples belonging to different cultivars. Food Quality and Preference, v.14, n.5, p.473-484, 2003.

25. MERRILL, A.L.; WATT, B.K. Energy values of foods: basis and derivation. Agricultural Handbook, n.74, Washington: USDA, 1973. 106p.

26. MINIM, V.P.R. Análise Sensorial: estudo com consumidores. 2 ed. Viçosa: UFV, 2010. 308p.

27. POINOT, P.; ARVISENET, G.; GRUA-PRIOL, J.; FILLONNEAU, C.; LE-BAIL, A.; PROST, C.; Influence of inulin on bread: kinetics and physico-chemical indicators of the formation of volatile compounds during baking. Food Chemistry, v.119, n.4, p.1474-1484, 2010.

28. RONKART, S.N.; PAQUOT, M.; FOUGNIES, C.; DEROANNE, C.; BLECKER, C.S. Effect of water uptake on amorphous inulin properties. Food Hydrocolloids, v.23, n.3, p.922-927, 2009.

29. SENDRA, E.; FAYOS, P.; LARIO, Y.; FERNÁNDEZ-LÓPEZ, J.; SAYASBARBERÁ, E.; PÉREZ-ALVAREZ, J.A.; Incorporation of citrus fibers in fermented milk containing probiotic bacteria. Food Microbiology, v.25, n.1, p.13-21, 2008.

30. TEIXEIRA, E.; MEINERT, E. M.; BARBETTA, P.A. Análise sensorial de alimentos. Florianópolis: UFSC, 1987. 60p. 
31. TOLONI, M.H.A.; LONGO-SILVA, G.; GOULART, R.M.M.; TADDEI, J.A.A.C. Introdução de alimentos industrializados e de alimentos de uso tradicional na dieta de crianças de creches públicas no município de São Paulo. Revista de Nutrição, v.24, n.1, p.61-70, 2011.

32. TONELI, J.T.C.L.; PARK, K.J.; MURR, F.E.X.; NEGREIROS, A.A. Efeito da umidade sobre a microestrutura da inulina em pó. Ciência e Tecnologia de Alimentos, v.28, n.1, p.122-131, 2008.

33. TACO - Tabela brasileira de composição de alimentos. $2^{\mathrm{a}}$ ed. Campinas: NEPA/UNICAMP, 2006. 114p.

34. VOLPINI-RAPINA, L.F.; SOKEI, F.R.; CONTI-SILVA, A.C. Sensory profile and preference mapping of orange cakes with addition of prebiotics inulin and oligofructose. Food Science and Technology, v.48, n.1, p.37-42, 2012.

35. WANG, Y. Prebiotics: present and future in food science and technology. Food Research International, v.42, n.1, p.8-12, 2009.

36. WONG, J.M.W.; KENDALL, C.W.C.; SOUZA, R.; AZADEH, E.; MARCHIE, A.; VIDGEN, E. The effect on the blood lipid profile of soy foods combined with a prebiotica randomized controlled trial. Metabolism Clinical and Experimental, v.59, n.1331, p.13-40, 2010.

37. ZAHN, S.; PEPKE, F.; ROHM, H. Effect of inulin as a fat replacer on texture and sensory properties of muffins. International Journal of Food Science and Technology, v.45, n.12, p.2531-2537, 2010.

38. ZIOBRO, R.; KORUS, J.; JUSZCZAK. L.; WITCZAK, T. Influence of inulin on physical characteristics and staling rate of gluten-free bread. Journal of Food Engineering, v.116, n.1, p.21-27, 2013. 